\title{
Confirmation of the three-factor model of the Assessing Emotions Scale (AES): Verification of the theoretical starting point
}

\author{
Bernadette Kun, Hedvig Balazs, Mate Kapitany, Robert Urban, and Zsolt Demetrovics \\ Eötvös Loránd University, Budapest, Hungary
}

\begin{abstract}
Several measures have been developed for the quantification of emotional intelligence. One widely applied method is the Assessing Emotions Scale, whose factor structure has attracted much scientific attention. The objective of the present study was to identify which of the previously suggested models are the most appropriate. By applying confirmatory factor analysis, we have tested the original one-, three-, four-, and six-factor solutions. Results confirmed the three-factor structure to be the most suitable solution. We suggest that the factors in this structure are better described by the labels "appraisal of emotions," "optimism and regulation of emotions," and "intrapersonal and interpersonal utilization of emotions." Supplemental materials for this article may be downloaded from http://brm.psychonomic-journals.org/content/supplemental.
\end{abstract}

Emotional intelligence (EI) is a relatively new field of research, with a history of under two decades. Its importance, however, is underscored by the rapidly growing number of studies and publications dealing with the phenomenon.

The concept of EI became well-known only after the book by Goleman (1995) became popular; however, the first definition of EI was given earlier, by Salovey and Mayer (1990, p. 189): "Emotional intelligence involves the ability to monitor one's own and others' feelings and emotions, to discriminate among them, and to use this information to guide one's thinking and actions." This early definition is now just one of many conceptualizations. As a result of the term's rapidly gaining popularity, several definitions, theories, and measures for this construct have been developed. The various perspectives hold that people with a high level of EI tend to have more positive traits, to be happier, or to be more successful in life than others (Chamorro-Premuzic, Bennett, \& Furnham, 2007; Martinez-Pons, 1997; van der Zee, Thijs, \& Schakel, 2002). In fact, several studies have pointed out that a higher level of EI correlates with more adaptive ways of coping (Salovey, Bedell, Detweiler, \& Mayer, 1999; Salovey, Stroud, Woolery, \& Epel, 2002), is associated with better interpersonal relations (Mayer, Caruso, \& Salovey, 1999), contributes to the achievement of better academic results (Parker, Summerfeldt, Hogan, \& Majeski, 2004; van der Zee et al., 2002), and is a protective factor in both physical and mental health (Austin, Saklofske, \& Egan, 2005; Tsaousis \& Nikolaou, 2005).

Because Salovey and Mayer (1990) have defined EI as a collection of abilities, their theory represents the abilitybased model. However, other authors (e.g., Bar-On, 1997;
Goleman, 1995) have presumed that EI is a mixture of traits and skills. For the assessment of EI, several measures on various theoretical bases have been created. Some of the operationalizations of EI (e.g., Levels of Emotional Awareness Scale-Lane, Quinlan, Schwartz, Walker, \& Zeitlin, 1990; Mayer-Salovey-Caruso Emotional Intelligence Test-Mayer, Salovey, \& Caruso, 2002) focus on the performance aspect of EI by means of performance tests. These measurements are derived from the abilitybased model of EI. However, the majority of operational definitions focus on the perceived level of EI by using self-rating questionnaires. These researchers aspired to assess those traits and skills that are interpreted as EI. Self-report questionnaires, in contrast with the abovementioned measures, which focus only on specific aspects of EI, cover the entire construct of EI. One of their great advantages is that they are able to assess various aspects of EI. Some disadvantages to mention, however, are that they measure "meta-experiences," correlate only slightly with academic intelligence (Barchard, 2003), and are less connected to emotions than performance tests; and it is quite difficult to define precisely which traits and skills belong to the umbrella concept of EI and which do not.

One of the most popular and most frequently used questionnaires, investigating all assumed aspects of EI, is the Assessing Emotions Scale (AES) developed by Schutte et al. (1998). The AES is based on the early three-branch EI model of Salovey and Mayer (1990), in which the three main dimensions are the appraisal and expression of emotion, the regulation of emotion, and the utilization of emotions in solving problems. The authors, however, identified all 33 items as belonging to the single global EI 
Table 1

Results of Former Studies Exploring the Factor Structure of the Assessing Emotions Scale (Schutte et al., 1998)

\begin{tabular}{|c|c|c|c|c|}
\hline Reference & Sample & Method & Results & Factors \\
\hline Schutte et al. (1998) & $\begin{array}{l}N=346, \text { convenient } \\
\text { community sample }\end{array}$ & $\begin{array}{l}\text { Exploratory factor } \\
\text { analysis }\end{array}$ & 1 factor (33 items) & Global emotional intelligence \\
\hline $\begin{array}{l}\text { Petrides \& Furnham } \\
(2000)\end{array}$ & $\begin{array}{l}N=260 \text {, university } \\
\text { students }\end{array}$ & $\begin{array}{l}\text { Exploratory factor } \\
\text { analysis }\end{array}$ & $\begin{array}{l}4 \text { factors ( } 26 \text { items of } \\
\text { the original } 33 \text { items) }\end{array}$ & $\begin{array}{l}\text { 1. Optimism/mood regulation } \\
\text { 2. Appraisal of emotions } \\
\text { 3. Social skills } \\
\text { 4. Utilization of emotions }\end{array}$ \\
\hline $\begin{array}{l}\text { Saklofske, Austin, \& } \\
\text { Minski (2003) }\end{array}$ & $\begin{array}{l}N=354 \text {, university } \\
\text { students }\end{array}$ & $\begin{array}{l}\text { Exploratory fac- } \\
\text { tor analysis and } \\
\text { confirmatory factor } \\
\text { analysis }\end{array}$ & $\begin{array}{l}1 \text { factor and } 4 \text { factors } \\
\text { ( } 29 \text { items of the origi- } \\
\text { nal } 33 \text { items) }\end{array}$ & $\begin{array}{l}\text { Global emotional intelligence and } \\
\text { 1. Optimism/mood regulation } \\
\text { 2. Appraisal of emotions } \\
\text { 3. Social skills } \\
\text { 4. Utilization of emotions }\end{array}$ \\
\hline $\begin{array}{l}\text { Austin, Saklofske, } \\
\text { Huang, \& McKenney } \\
\text { (2004) }\end{array}$ & $\begin{array}{l}N=500, \text { university } \\
\text { students }\end{array}$ & $\begin{array}{l}\text { Exploratory factor } \\
\text { analysis }\end{array}$ & $\begin{array}{l}3 \text { factors ( } 24 \text { items of } \\
\text { the original } 33 \text { items) }\end{array}$ & $\begin{array}{l}\text { 1. Optimism/positivity } \\
\text { 2. Regulating/using emotions } \\
\text { 3. Appraisal of emotions }\end{array}$ \\
\hline $\begin{array}{l}\text { Gignac, Palmer, } \\
\text { Manocha, \& Stough } \\
(2005)\end{array}$ & $\begin{array}{l}N=367, \text { convenient } \\
\text { community sample }\end{array}$ & $\begin{array}{l}\text { Confirmatory factor } \\
\text { analysis }\end{array}$ & $\begin{array}{l}\text { Not verified any } \\
\text { structure ( } 28 \text { items of } \\
\text { the original } 33 \text { items) }\end{array}$ & $\begin{array}{l}\text { 1. Appraisal of emotions in the self } \\
\text { 2. Appraisal of emotions in others } \\
\text { 3. Emotional expression } \\
\text { 4. Emotional regulation of the self } \\
\text { 5. Emotional regulation of others } \\
\text { 6. Utilization of emotions for problem solving }\end{array}$ \\
\hline Keele \& Bell (2008) & $\begin{array}{l}N=206, \text { convenient } \\
\text { community sample }\end{array}$ & $\begin{array}{l}\text { Exploratory factor } \\
\text { analysis }\end{array}$ & $\begin{array}{l}4 \text { factors (the number } \\
\text { of items is unknown) }\end{array}$ & $\begin{array}{l}\text { 1. Optimism/mood regulation } \\
\text { 2. Appraisal of emotions } \\
\text { 3. Social skills } \\
\text { 4. Utilization of emotions }\end{array}$ \\
\hline
\end{tabular}

factor (Schutte et al., 1998). An internal consistency analysis showed a Cronbach's $\alpha$ of .90, and the 2-week testretest reliability of the questionnaire was .78 . AES showed evidence of predictive validity in that incoming college students' EI scores predicted their end-of-year grade-point average. AES also has appropriate discriminant validity. It is different from cognitive ability (assessed by the Scholastic Assessment Test) and is not significantly related to four of the Big Five personality dimensions (Schutte et al., 1998).

Several later studies examining the structure of the questionnaire suggested multifactorial solutions instead of the single-factor solution (see Table 1). Petrides and Furnham (2000) identified four factors by means of exploratory factor analysis - optimism/mood regulation, appraisal of emotions, social skills, and utilization of emotions. Later, Saklofske, Austin, and Minski (2003) confirmed this factor structure, applying both confirmatory and exploratory factor analysis; they have not, however, disproved the unifactorial structure. Their results also suggest that the four factors belong to one main factor - the global EI factor, described by Schutte et al. (1998). Later, members of the same team (Austin, Saklofske, Huang, \& McKenney, 2004) elaborated a modified 41-item version of the AES containing 20 reverse items (the original scale contained only 3 ). As a result of the exploratory factor analysis executed on this measure, three factors emerged that are also present in the above-mentioned four-factor structure: optimism/ mood regulation, utilization of emotions, and appraisal of emotions. The authors analyzed the original 33-item version as well, and their analysis similarly presented three factors, which, loaded by 24 items, were optimism/ positivity, regulating/using emotions, and appraisal of emotions.

Gignac, Palmer, Manocha, and Stough (2005), in analyzing these results, concluded that neither the unifactorial nor the four-factor solution gives the most acceptable answer. As an alternative, one conclusion of their qualitative study was a proposed six-factor structure fitting the original theory. Twenty-eight items of the original questionnaire were included in the six factors: appraisal of emotions in the self, appraisal of emotions in others, emotional expression, emotional regulation of the self, emotional regulation of others, and utilization of emotions for problem solving. Although confirmatory factor analysis was unable to verify the independence of these factors, the authors pointed out that the four-factor solution of Petrides and Furnham (2000) was not supported either. Finally, the principal component analysis of Keele and Bell (2008) identified four factors as well (the structure of these factors was unfortunately not published), which they labeled in the same way that Petrides and Furnham had done earlier.

\section{Objectives}

Because previous studies have been unable to present an unambiguous solution regarding the structure of EI as measured by the AES, our objective was to test these proposals and to show which of the published structures is most suitable for the description and assessment of EI. Also, we intended to test whether the EI model suggested by Schutte et al. (1998), based on the three-dimensional theoretical starting point of Salovey and Mayer (1990), could be confirmed on a Hungarian sample. 


\section{METHOD}

\section{Participants}

The sample consisted of 702 persons from a convenient community sample. A total of 11 questionnaires were dropped due to the high proportion of missing values (higher than 10\%). In order to collect a heterogeneous sample, participants were recruited out of students of various universities and employees of diverse companies. All questionnaires were filled in voluntarily, and no remuneration was offered for participation. The mean age was 25.5 years (18-75 years, $S D=6.73$ ), $55.5 \%$ of the sample were male, $15.5 \%$ had graduated from college or university, and $71.4 \%$ had secondary school qualification.

\section{Measures and Procedure}

Sociodemographic data. Ten questions were devised to reveal the following sociodemographic data of the participants: sex, age, place of usual residence, educational qualifications of the participant and his/her parents, occupation, and the number of persons living in the participant's household.

EI. The AES (Schutte et al., 1998) is a self-report questionnaire with 33 items that contains 3 reverse items $(5,28,33)$. After summarizing the scores of the 5-point Likert scales, where $1=$ strongly disagree and $5=$ strongly agree, we determined the perceived level of EI of the participant. The authors created the Hungarian version of the questionnaire by translation and back-translation, and inconsistencies were resolved. The questionnaire is referred to by many names in the literature (e.g., Schutte Self-Report Emotional Intelligence [SSREI] scale, Emotional Intelligence Scale [EIS], Schutte Self-Report Inventory [SSRI]). The reason for this is possibly that, in the original publication of the questionnaire (Schutte et al., 1998), the authors did not provide a name. We use "Assessing Emotions Scale," which the original authors used in a later publication (Schutte, Malouff, \& Bhullar, 2009).

The questionnaires were completed in groups of 10-15 persons during 2007 and 2008. In all groups, a well-trained assistant informed the participants about the research and the tasks. The assistant ensured that all participants filled in the questionnaire on their own. Each participant received a separate questionnaire and completed that individually.

Statistical analysis. SPSS 16.0 and AMOS 4.0 statistical software were used for statistical analyses. We applied confirmatory factor analysis for testing single-, three-, four-, and six-factor structures.
The four-factor model of Keele and Bell (2008), whose structure, according to those authors, shows similarities with the AES structure of Petrides and Furnham (2000), has not been examined, because the authors did not publish details of the content of specific factors.

\section{RESULTS}

Internal consistency of the AES for all 33 items proved to be appropriate (Cronbach's $\alpha=.882$ ). We can say of all four models that the $\chi^{2}$ tests give significant results; however, we have used less conservative fit indexes to compare the different factor structures. These so-called liberal fit indexes are of basic importance during confirmatory factor analysis. Computation of these indexes is reasonable and necessary, especially when dealing with large samples $(N>200)$ for which the more conservative index, model $\chi^{2}$, is significant in almost all of the cases (Kline, 2005).

Before comparing the fit indexes, however, we already had to exclude the six-factor structure, because the analysis showed that the implied covariance matrix of the six-factor structure was not positive definite. In order to decrease multicollinearity, we have repeated the analysis followed by the transformation of the items into $z$ scores (standardization). The implied covariance matrix was also not positive definite due to the high multicollinearity identified in the six-factor structure. The third factor of this model, containing only two items labeled as "emotional expression," shows an extremely strong relationship with the fourth factor ("emotion regulation of the self" [estimated $r=.96]$ ) and with the fifth factor ("emotion regulation of others" [estimated $r=.88]$ ). The multicollinearity here implies that these three factors might represent only one factor.

We used the following method to analyze the remaining three structures. As a first step, we analyzed fit indexes for all three models without supposing any error covariances between items. Since different factor solutions in-

Table 2

Fit Indexes of the Confirmatory Factor Analysis Testing the One-, Three-, Four-, and Six-Factor Models

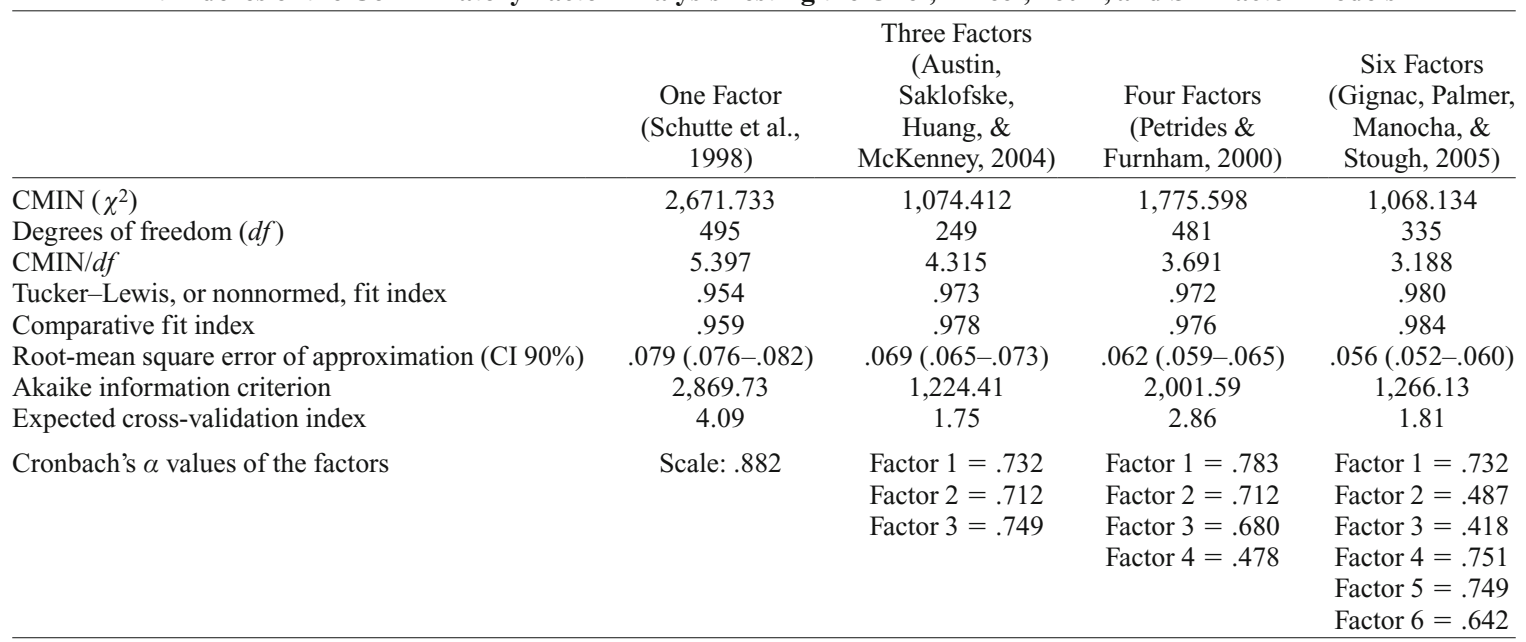

Note-CMIN, minimum $\chi^{2}$; CI 90\%, confidence interval for $p=.90$. 
clude different lists of items (see Table 1) and they are not hierarchical models, the usual $\chi^{2}$ difference test is not an appropriate method to compare the different solutions (Kline, 2005). Liberal fit indexes support the disproval of the single-factor model. Although the Tucker-Lewis fit index (TLI) and comparative fit index (CFI) show optimal (higher than .95) values, the upper threshold of the confidence interval of the RMSEA value is slightly higher than .08. RMSEA values lower than .05 are ideal, between .05 and .08 suggest reasonable fit, and .10 or above indicates poor fit (Browne \& Cudeck, 1993). However, personality constructs even with larger sample sizes may not always show RMSEA values less than .05 due to the complexity of the models including large number of items and factors. Although the generally used fixed cutoff points have been criticized (e.g., Chen, Curran, Bollen, Kirby, \& Paxton, 2008), supplementing this fit index with other fit indexes provides the full picture of the model fit. The ratio of CMIN (minimum $\chi^{2}$ ) and degrees of free$\operatorname{dom}(d f)$ is ineligible for the one-factor structure as well, because it exceeds the just acceptable limiting value of 5 (Marsh \& Hocevar, 1985). For the three- and four-factor models, however, all the liberal fit indexes (TLI, CFI, and RMSEA) and the ratio of CMIN and $d f$ are within the preferred range (Table 2). Although the six-factor model has been disproved for the above-mentioned reasons, its fit indexes are also shown in Table 2.

As a second step, we have investigated how the degree of fit of the three models changes if we assume covariance between error terms of certain items. Based on the analysis of modification indexes and the content, five pairs of items were considered to have covariance: Items 3 and 10 , 5 and 25, 7 and 27, 17 and 20, and 24 and 30. Analysis carried out this way resulted in improved fit of all three models (Table 3).

Means and standard deviations of items and interitem correlations are summarized in Table 4, and Table 5 shows standardized regression weights pertaining to the three models.
It is apparent that basic fit indexes $(\mathrm{CMIN} / d f$ and RMSEA) of all three models fall into the optimal range. Nevertheless, the examination of further fit indexes provides a chance to select the most suitable model out of the three solutions. In the case of nonhierarchical models, model selection is usually based on predictive fit indexes (Brown, 2006). As regards the two indexes, AIC (Akaike information criterion; see Akaike, 1973) and ECVI (expected cross-validation index; see Browne \& Cudeck, 1993), the most suitable model is the one characterized by the lowest values (Brown, 2006). On this basis, the threefactor solution seems to be the most suitable (Figure 1). Besides lower AIC and ECVI indexes, a further weakness of the four-factor model is that it contains one factor covering only two items, and the identification would be better if more items identified the factor in question. The value of Cronbach's $\alpha$ was also lower than expected for this item (.478).

Subscales of the three-factor AES questionnaire confirmed by this study show good reliability. We used Cronbach's $\alpha$ value and mean interitem correlations (MICs). The recommended optimal range of MIC is .2-.4 (Briggs $\&$ Cheek, 1986). Cronbach's $\alpha$ for the first factor (including items $5,15,18,25,29,32$, and 33) is .732, and MIC = .40. Cronbach's $\alpha$ values are .712 for the second factor (including Items 3, 10, 12, 14, 19, 21, and 28) and .749 for the third factor (including Items 2, 6, 7, 17, 20, 23, 24, 27, 30 , and 31), whereas the MIC was .21 in both cases.

After the revision of the items loading to these factors, however, we suggest reconsidering the labels of the factors proposed by Austin et al. (2004). The factor called the "appraisal of emotions" covers items concerning identification and interpretation of emotions of the self and others; therefore this label is regarded as appropriate. For the second factor, however, called "optimism/positivity" by Austin and colleagues, we suggest the label "optimism and regulation of emotions." In contrast with the former label, this one lays more emphasis on the fact that these items refer not to the optimism of the person in general

Table 3

Fit Indexes of the Confirmatory Factor Analysis Testing the One-, Three-, and Four-Factor Models After Freeing the Covariance Between Certain Error Terms (See in the Text)

\begin{tabular}{|c|c|c|c|}
\hline & $\begin{array}{c}\text { One Factor } \\
\text { (Schutte et al., } \\
1998)\end{array}$ & $\begin{array}{c}\text { Three Factors } \\
\text { (Austin, } \\
\text { Saklofske, } \\
\text { Huang, \& } \\
\text { McKenney, 2004) }\end{array}$ & $\begin{array}{c}\text { Four Factors } \\
\text { (Petrides \& } \\
\text { Furnham, 2000) }\end{array}$ \\
\hline $\operatorname{CMIN}\left(\chi^{2}\right)$ & $2,137.321$ & 768.833 & $1,575.888$ \\
\hline Degrees of freedom $(d f)$ & 490 & 244 & 476 \\
\hline $\mathrm{CMIN} / d f$ & 4.362 & 3.151 & 3.311 \\
\hline Tucker-Lewis, or nonnormed, fit index & .965 & .983 & .976 \\
\hline Comparative fit index & .969 & .986 & .979 \\
\hline Root-mean square error of approximation (CI 90\%) & $.070(.067-.073)$ & $.056(.051-.060)$ & $.058(.055-.061)$ \\
\hline Akaike information criterion & $2,345.321$ & 928.833 & $1,811.888$ \\
\hline Expected cross-validation index & 3.399 & 1.346 & 2.626 \\
\hline \multirow[t]{4}{*}{ Cronbach's $\alpha$ values of the factors } & Scale: .882 & Factor $1=.732$ & Factor $1=.783$ \\
\hline & & Factor $2=.712$ & Factor $2=.712$ \\
\hline & & Factor $3=.749$ & Factor $3=.680$ \\
\hline & & & Factor $4=.478$ \\
\hline
\end{tabular}

Note-CMIN, minimum $\chi^{2} ;$ CI 90\%, confidence interval for $p=.90$. 
Table 4

Correlation Values, Means (Ms), and Standard Deviations (SDs) of the 33 Items of the Assessing Emotions Scale

\begin{tabular}{|c|c|c|c|c|c|c|c|c|c|c|c|c|c|c|c|c|}
\hline & 1 & 2 & 3 & 4 & 5 & 6 & 7 & 8 & 9 & 10 & 11 & 12 & 13 & 14 & 15 & 16 \\
\hline 1 & 1.00 & & & & & & & & & & & & & & & \\
\hline 2 & $.25^{* *}$ & 1.00 & & & & & & & & & & & & & & \\
\hline 3 & $.13^{* *}$ & $.19^{* *}$ & 1.00 & & & & & & & & & & & & & \\
\hline 4 & $.15^{* *}$ & $.16^{* *}$ & $.14^{* *}$ & 1.00 & & & & & & & & & & & & \\
\hline 5 & $-.17^{* *}$ & .01 & -.01 & $-.14^{* *}$ & 1.00 & & & & & & & & & & & \\
\hline 6 & $.13^{* *}$ & $.15^{* *}$ & -.01 & $.17^{* *}$ & $-.10^{* *}$ & 1.00 & & & & & & & & & & \\
\hline 7 & .07 & .05 & -.01 & .05 & $-.08^{*}$ & $.18^{* *}$ & 1.00 & & & & & & & & & \\
\hline 8 & $.17^{* *}$ & $.10^{* *}$ & $.07^{*}$ & $.19^{* *}$ & $-.15^{* *}$ & $.20^{* *}$ & $.20^{* *}$ & 1.00 & & & & & & & & \\
\hline 9 & $.29^{* *}$ & $.09^{*}$ & $.17^{* *}$ & $.15^{* *}$ & $-.16^{* *}$ & $.10^{* *}$ & -.01 & $.23^{* *}$ & 1.00 & & & & & & & \\
\hline 10 & $.20^{* *}$ & $.17^{* *}$ & $.42^{* *}$ & $.18^{* *}$ & -.07 & .06 & .01 & $.19^{* *}$ & $.28^{* *}$ & 1.00 & & & & & & \\
\hline 11 & $.17^{* *}$ & $.11^{* *}$ & $.10^{* *}$ & $.15^{* *}$ & $-.14^{* *}$ & $.14^{* *}$ & $.12^{* *}$ & $.32^{* *}$ & $.09^{* *}$ & $.22^{* *}$ & 1.00 & & & & & \\
\hline 12 & $.32^{* *}$ & $.25^{* *}$ & $.15^{* *}$ & $.17^{* *}$ & $-.15^{* *}$ & $.08^{*}$ & .07 & $.18^{* *}$ & $.29^{* *}$ & $.31^{* *}$ & $.22^{* *}$ & 1.00 & & & & \\
\hline 13 & $.10^{* *}$ & $.15^{* *}$ & $.17^{* *}$ & $.19^{* *}$ & $-.08^{*}$ & $.12^{* *}$ & $.09^{*}$ & $.22^{* *}$ & .07 & $.25^{* *}$ & $.25^{* *}$ & $.19^{* *}$ & 1.00 & & & \\
\hline 14 & $.22^{* *}$ & $.10^{* *}$ & $.22^{* *}$ & $.11^{* *}$ & -.07 & .03 & .04 & $.15^{* *}$ & $.21^{* *}$ & $.30^{* *}$ & $.17^{* *}$ & $.32^{* *}$ & $.19^{* *}$ & 1.00 & & \\
\hline 15 & $.23^{* *}$ & $.09^{*}$ & $.11^{* *}$ & $.20^{* *}$ & $-.36^{* *}$ & $.07^{*}$ & $.16^{* *}$ & $.11^{* *}$ & $.19^{* *}$ & $.13^{* *}$ & $.14^{* *}$ & $.24^{* *}$ & $.11^{* *}$ & $.20^{* *}$ & 1.00 & \\
\hline 16 & -.05 & -.02 & .05 & $.20^{* *}$ & -.01 & .06 & .01 & $.13^{* *}$ & .04 & $.15^{* *}$ & $.14^{* *}$ & .07 & $.15^{* *}$ & $.12^{* *}$ & $.09^{*}$ & 1.00 \\
\hline 17 & $.20^{* *}$ & $.28^{* *}$ & $.21^{* *}$ & $.20^{* *}$ & $-.08^{*}$ & $.21^{* *}$ & $.15^{* *}$ & $.19^{* *}$ & $.15^{* *}$ & $.29^{* *}$ & $.17^{* *}$ & $.26^{* *}$ & $.22^{* *}$ & $.23^{* *}$ & $.13^{* *}$ & $.13^{* *}$ \\
\hline 18 & $.21^{* *}$ & $.11^{* *}$ & $.11^{* *}$ & $.19^{* *}$ & $-.41^{* *}$ & $.18^{* *}$ & $.11^{* *}$ & $.20^{* *}$ & $.30^{* *}$ & $.09^{*}$ & $.17^{* *}$ & $.28^{* *}$ & $.16^{* *}$ & $.18^{* *}$ & $.39^{* *}$ & .07 \\
\hline 19 & $.29^{* *}$ & $.19^{* *}$ & $.13^{* *}$ & .07 & $-.17^{* *}$ & $.12^{* *}$ & .04 & $.07^{*}$ & $.38^{* *}$ & $.18^{* *}$ & .03 & $.31^{* *}$ & .07 & $.15^{* *}$ & $.24^{* *}$ & -.06 \\
\hline 20 & $.18^{* *}$ & $.20^{* *}$ & $.13^{* *}$ & $.18^{* *}$ & -.07 & $.19^{* *}$ & $.20^{* *}$ & $.16^{* *}$ & $.09^{* *}$ & $.20^{* *}$ & $.12^{* *}$ & $.15^{* *}$ & $.12^{* *}$ & $.16^{* *}$ & $.12^{* *}$ & $.13^{* *}$ \\
\hline 21 & $.16^{* *}$ & $.15^{* *}$ & $.16^{* *}$ & .07 & -.05 & -.04 & .00 & .00 & $.22^{* *}$ & $.22^{* *}$ & .02 & $.27^{* *}$ & .07 & $.09^{*}$ & $.13^{* *}$ & .02 \\
\hline 22 & $.29^{* *}$ & $.12^{* *}$ & $.18^{* *}$ & $.13^{* *}$ & $-.14^{* *}$ & .07 & .07 & $.16^{* *}$ & $.50^{* *}$ & $.20^{* *}$ & $.13^{* *}$ & $.28^{* *}$ & $.10^{* *}$ & $.25^{* *}$ & $.28^{* *}$ & $.09^{*}$ \\
\hline 23 & $.10^{* *}$ & $.23^{* *}$ & $.23^{* *}$ & $.14^{* *}$ & .02 & $.14^{* *}$ & $.09^{*}$ & $.21^{* *}$ & $.12^{* *}$ & $.23^{* *}$ & $.23^{* *}$ & $.22^{* *}$ & $.20^{* *}$ & $.15^{* *}$ & $.07^{*}$ & $.15^{* *}$ \\
\hline 24 & $.19^{* *}$ & $.21^{* *}$ & $.09^{* *}$ & $.27^{* *}$ & $-.16^{* *}$ & $.18^{* *}$ & .07 & $.28^{* *}$ & $.16^{* *}$ & $.20^{* *}$ & $.26^{* *}$ & $.24^{* *}$ & $.25^{* *}$ & $.18^{* *}$ & $.17^{* *}$ & $.17^{* *}$ \\
\hline 25 & $.30^{* *}$ & $.14^{* *}$ & $.11^{* *}$ & $.18^{* *}$ & $-.59^{* *}$ & $.19^{* *}$ & $.15^{* *}$ & $.23^{* *}$ & $.24^{* *}$ & $.19^{* *}$ & $.21^{* *}$ & $.27^{* *}$ & $.17^{* *}$ & $.23^{* *}$ & $.53^{* *}$ & .06 \\
\hline 26 & $.14^{* *}$ & $.17^{* *}$ & .03 & $.25^{* *}$ & $-.24^{* *}$ & $.21^{* *}$ & $.19^{* *}$ & $.36^{* *}$ & $.14^{* *}$ & $.12^{* *}$ & $.30^{* *}$ & $.18^{* *}$ & $.19^{* *}$ & $.10^{* *}$ & $.20^{* *}$ & $.11^{* *}$ \\
\hline 27 & $.10^{* *}$ & $.14^{* *}$ & .03 & .06 & $-.11^{* *}$ & $.19^{* *}$ & $.43^{* *}$ & $.22^{* *}$ & .04 & .07 & $.18^{* *}$ & $.10^{* *}$ & $.12^{* *}$ & .07 & $.18^{* *}$ & -.01 \\
\hline 28 & $-.17^{* *}$ & $-.23^{* *}$ & $-.31^{* *}$ & -.05 & $.10^{* *}$ & -.02 & .07 & -.04 & $-.15^{* *}$ & $-.27^{* *}$ & .00 & $-.16^{* *}$ & $-.08^{*}$ & $-.13^{* *}$ & $-.16^{* *}$ & $.07^{*}$ \\
\hline 29 & $.19^{* *}$ & $.09^{* *}$ & $.15^{* *}$ & $.16^{* *}$ & $-.32^{* *}$ & $.15^{* *}$ & $.17^{* *}$ & $.17^{* *}$ & $.17^{* *}$ & $.16^{* *}$ & $.12^{* *}$ & $.19^{* *}$ & $.17^{* *}$ & $.16^{* *}$ & $.39^{* *}$ & .04 \\
\hline 30 & $.21^{* *}$ & $.14^{* *}$ & .04 & $.30^{* *}$ & $-.22^{* *}$ & $.28^{* *}$ & $.13^{* *}$ & $.26^{* *}$ & $.13^{* *}$ & $.17^{* *}$ & $.26^{* *}$ & $.16^{* *}$ & $.28^{* *}$ & $.11^{* *}$ & $.20^{* *}$ & $.18^{* *}$ \\
\hline 31 & $.19^{* *}$ & $.14^{* *}$ & $.16^{* *}$ & $.09^{*}$ & $-.07^{*}$ & $.15^{* *}$ & $.13^{* *}$ & $.21^{* *}$ & $.21^{* *}$ & $.29^{* *}$ & $.21^{* *}$ & $.34^{* *}$ & $.22^{* *}$ & $.23^{* *}$ & $.19^{* *}$ & $.08^{*}$ \\
\hline 32 & $.19^{* *}$ & $.12^{* *}$ & $.08^{*}$ & $.16^{* *}$ & $-.22^{* *}$ & $.17^{* *}$ & $.16^{* *}$ & $.20^{* *}$ & $.19^{* *}$ & $.15^{* *}$ & $.16^{* *}$ & $.24^{* *}$ & $.20^{* *}$ & $.15^{* *}$ & $.27^{* *}$ & $.14^{* *}$ \\
\hline 33 & $-.22^{* *}$ & $-.10^{* *}$ & -.07 & $-.16^{* *}$ & $.39^{* *}$ & $-.07^{*}$ & -.07 & $-.15^{* *}$ & $-.21^{* *}$ & $-.10^{* *}$ & $-.09^{* *}$ & $-.17^{* *}$ & $-.12^{* *}$ & $-.11^{* *}$ & $-.26^{* *}$ & -.04 \\
\hline$M$ & 2.82 & 2.90 & 2.64 & 3.09 & 1.25 & 2.88 & 2.02 & 3.23 & 2.92 & 2.85 & 2.60 & 2.38 & 5.65 & 2.91 & 2.67 & 3.14 \\
\hline$S D$ & 0.95 & 0.98 & 0.95 & 0.80 & 1.08 & 1.11 & 1.15 & 0.92 & 0.86 & 0.95 & 1.14 & 0.95 & 1.05 & 0.78 & 0.94 & 0.84 \\
\hline
\end{tabular}

Note-For single-page versions of this table and Table 5, see the supplemental materials. ${ }^{*}$ Correlation is significant at the .05 level. ${ }^{* *}$ Correlation is significant at the .01 level.

but to the positive attitude resulting from his/her success in the regulation of emotions (e.g., "When I experience a positive emotion, I know how to make it last."). Finally, for the third factor, we propose to apply the label "intrapersonal and interpersonal utilization of emotions" instead of the former "regulating and using emotions." This new label denotes that this third factor also implies the dimension formerly called "social skills" by other authors. In our opinion, items of social skills are parallel to those of utilization of emotions in the questionnaire. Items belonging to this factor refer rather to the ability to utilize emotions, both in the intrapsychic dimension and in interpersonal situations, and not to the ability to regulate emotions (e.g., "When I am in a positive mood, I am able to come up with new ideas," or "I compliment others when they have done something well."). The dimension of the ability to regulate emotions is better represented by the items of the second factor.

In the present analysis, the associations between sociodemographic variables (sex, age, and education) and the aspects of EI have been tested with a multiple-indicatorsmultiple-causes (MIMIC) analysis. This MIMIC analysis provides an opportunity to simultaneously investigate the possible effects of the variables concerning the separate dimensions of EI. Based on the results, only sex as an exogenic variable has a significant effect on the latent factor of appraisal of emotions, whereas the other two factors showed no significant effects (see Table 6). Women score significantly higher than men on the scale of appraisal of emotions $(1=$ male, $2=$ female $)$.

\section{DISCUSSION}

The objective of our study was to define the most appropriate factor structure for the AES. This is the first study that has attempted to examine all formerly proposed factor structures of AES in the same sample. Out of the tested four structures, the three-factor concept, which conforms the most closely to the original model of Salovey and Mayer (1990), proved to be the most plausible. The six-factor model (Gignac et al., 2005) has been unequivocally rejected because the analysis showed extremely high multicollinearity. In the course of comparing the other three models, the unifactorial proved to be the weakest solution, whereas the three-factor structure proved to be the most convincing. However, we have refined the three models by means of exploring error covariances. Results acquired this way confirmed the earlier results. Although 
Table 4

(Continued)

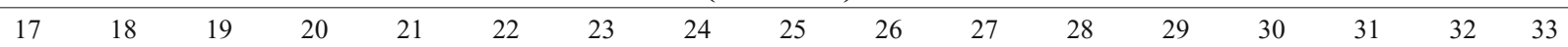

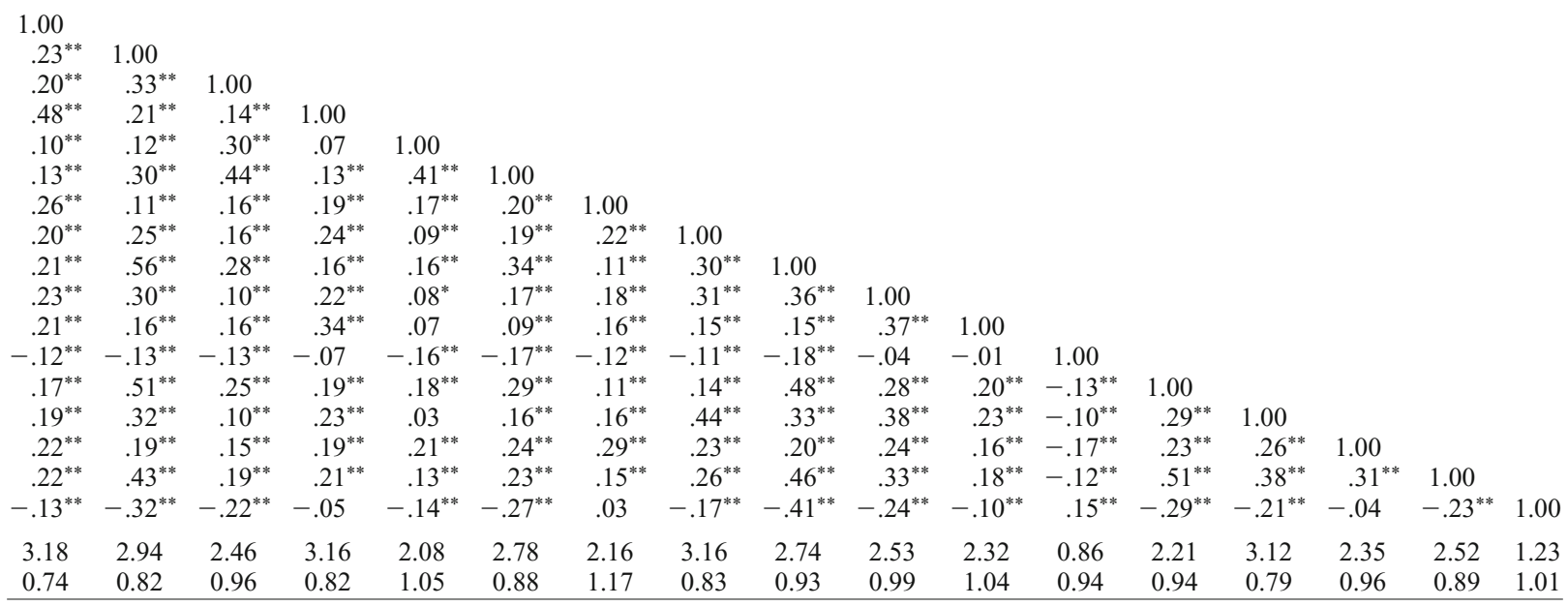

${ }^{*}$ Correlation is significant at the .05 level. ${ }^{* *}$ Correlation is significant at the .01 level.

all three models have met the basic expectations, on the basis of further analysis of the more specific indexes, the three-factor structure seemed to be the most plausible. This decision was also supported by the fact that the fourfactor model contains one factor covering only two items, and the identification would be better if more items identified the factor in question.

This result is important, because it confirms the validity of the original three-factor EI concept (Salovey \& Mayer, 1990), which was applied as a theoretical starting point by Schutte et al. (1998), however, with little empirical support. From this perspective, it is important to emphasize that Salovey and Mayer supported the model by their own measure only. Our results, which confirmed the three-factor structure on another questionnaire, contribute to the validation of the concept. The concordance between the original three-factor theoretical model and the threefactor structure of AES confirmed by the present study might be best explained by examining the content of each factor. The first factor, labeled "appraisal of emotions" in the theoretical model, contains items such as "I am aware of the nonverbal messages I send others" and "I can tell how people are feeling by listening to the tone of their voice." These items, therefore, refer to the adequate ap- praisal of signs and messages concerning one's own or others' emotions. The second factor, originally labeled as "regulation of emotions" in the theory of Salovey and Mayer, contains items such as "I know why my emotions change" and "I have control over my emotions." These items assess how the person evaluates his own abilities of changing and regulating emotions. The third factor, originally called "utilization of emotions," contains items such as "When my mood changes, I see new possibilities" and "When I am in a positive mood, solving problems is easy for me." These latter sentences concern how the person perceives and to what extent he/she can use his/her mood changes in cognitive processes.

Besides confirming the three-factor structure proposed by Austin et al. (2004), however, we suggest a reconsideration of the former labels of the factors. The labels we suggest, "appraisal of emotions," "optimism and regulation of emotions," and the "intrapersonal and interpersonal utilization of emotions," not only better describe the content of each factor, but are more in line with the theoretical starting point of Schutte et al. (1998), who based their work on the model of Salovey and Mayer (1990). The early, three-branch EI model of Salovey and Mayer, proposing the dimensions appraisal and expression of 


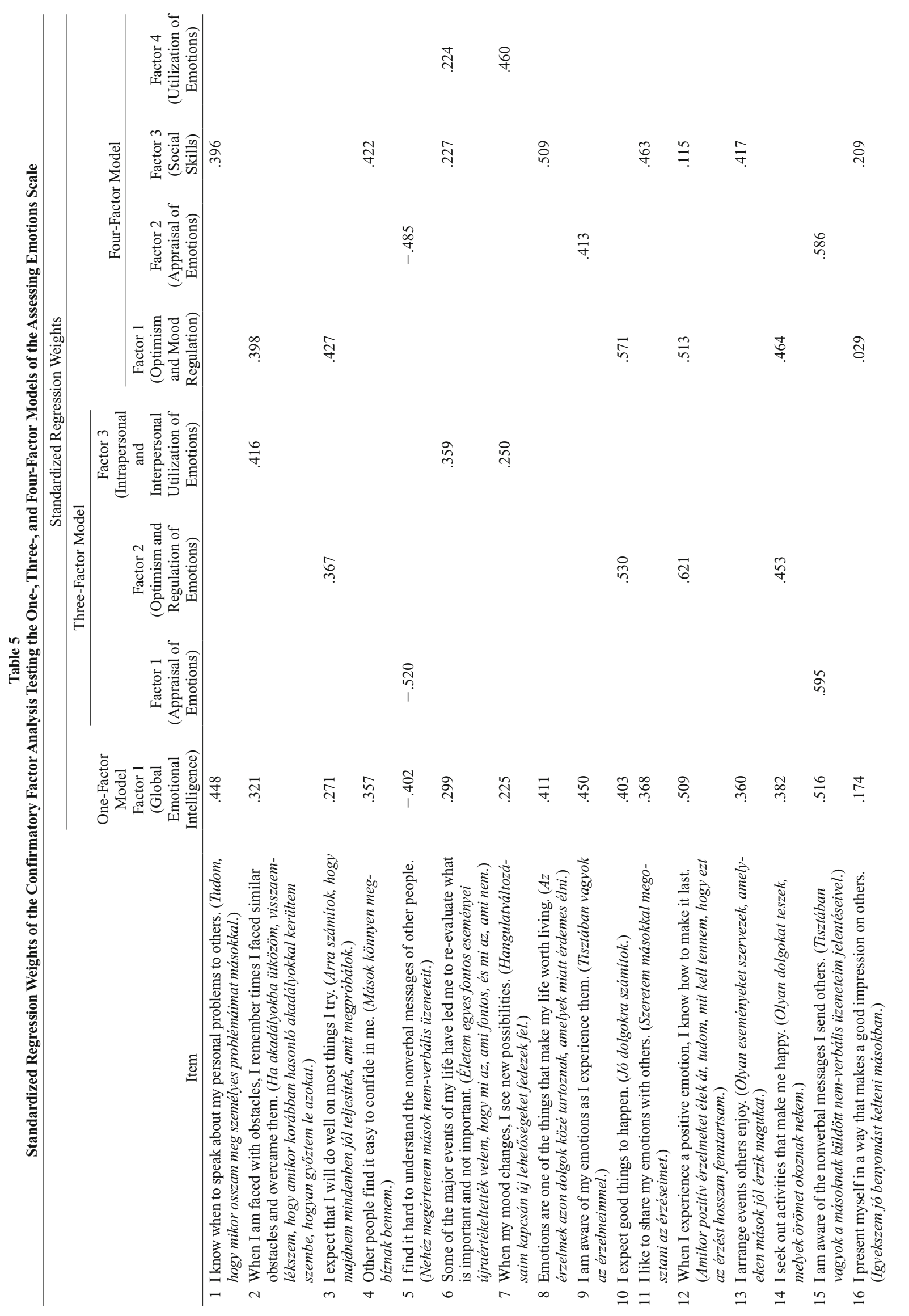




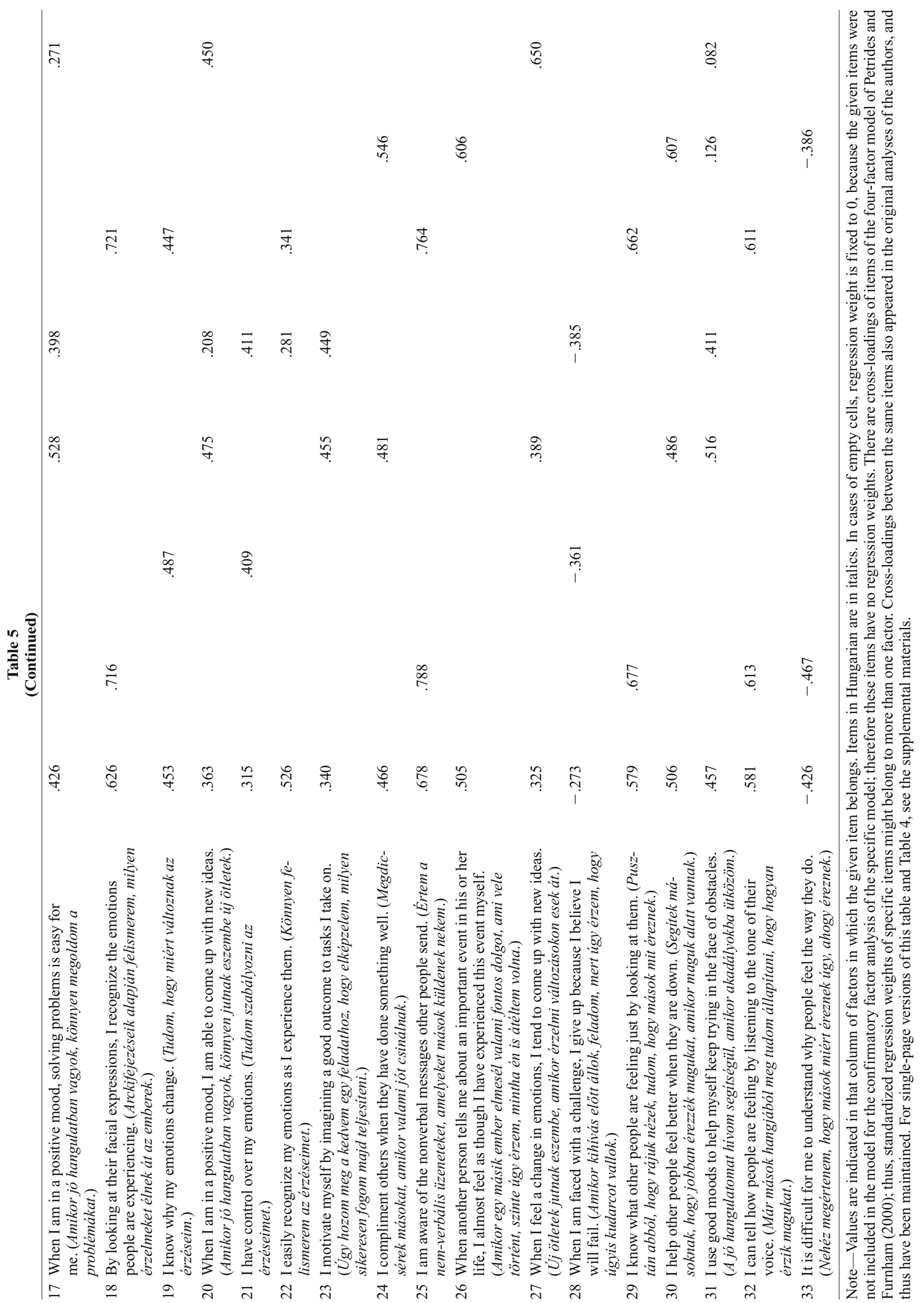




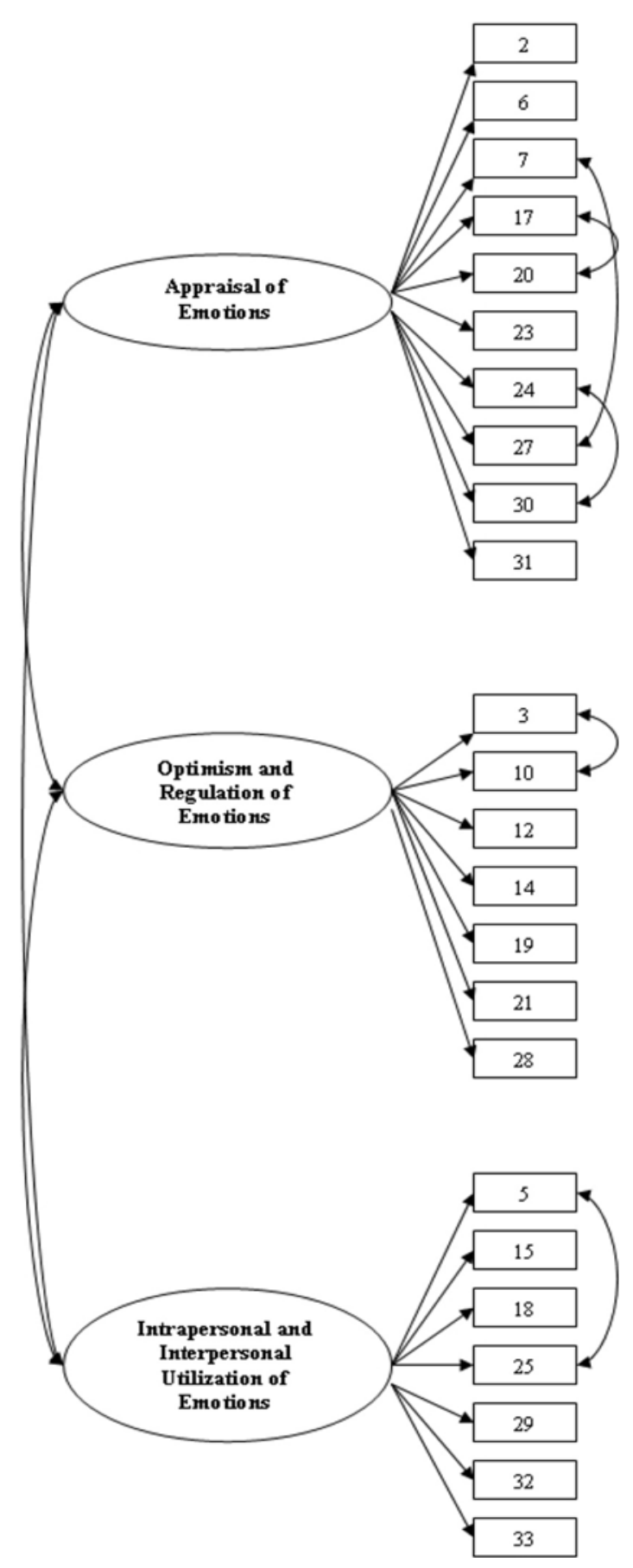

Figure 1. Three-factor solution of the Assessing Emotions Scale.

emotion, regulation of emotion, and utilization of emotions in solving problems, is clearly present in the AES questionnaire, even though the dimensions do not cover exactly the same content. For the third factor, we considered the dimensions labeled "utilization of emotions" and "social skills"-factors sometimes disparate in other authors' analyses, but loading to one factor in our study - to be reflected in the new label. Although the intrapersonal aspect of the utilization of emotions appears in individual problem-solving situations, the interpersonal aspect of the same component of EI is consistent with social skills.

In the present study, we have investigated the possible effects of sex, age, and school education by means of a MIMIC analysis with regards to the three-factor structure. Age and education had no significant effect on the factors in the model, whereas sex as an exogenic variable had a significant path only to the appraisal-of-emotions factor. Therefore, women gave higher ratings related to the more precise identification and more successful appraisal of their own emotions. This result is in accordance with previous research, suggesting that women perform better regarding EI and the appraisal of emotions than men do (e.g., Mayer et al., 1999; Mayer et al., 2002; Palmer, Gignac, Manocha, \& Stough, 2005). At the same time, the present study did not confirm the differences regarding education connected to academic performance and age that are suggested by other studies (e.g., Bar-On, 1997; Parker et al., 2004). It is worthwhile to note, however, that academic performance was not assessed directly; our questions concerned only school qualification. This sociodemographic variable, however, is a more complex factor than is academic performance in itself. This might be a reason for not proving the expected effect of school education. Also, it is more advantageous to examine the role of age in longitudinal studies (e.g., Caruso, Mayer, \& Salovey, 2002; Nagy, Oláh, \& Tóth, 2009) in the future; the present cross-sectional study does not necessarily provide a relevant answer to this question.

With respect to our results, we suggest that separate scores, completed on the three subscales of AES, presented by Austin et al. (2004) and confirmed by our study, are worth taking into account when this questionnaire is applied. In this case, in contrast with the single-factor model, these factors contribute to the achievement of a more differentiated picture of the characteristics of the participants' perceived level of EI. For a better understanding of the nature of these dimensions, it might be worthwhile to examine their correlations with ability-based EI measures and/or specific personality dimensions.

Several different measures of EI are being used in practice. On this new field of science, there is no real integration yet; we cannot speak about a generally accepted and confirmed model. This is one reason why it is important to emphasize that our results concern only one specific concept of EI and we have to be very careful about generalizing the results on all EI concepts. With respect to the EI concept operationalized by the AES, however, the three-factor model seems to be preferable. Considering that EI is a young construct, we have to face open questions regarding the nature and operationalization of the concept. Our tests of the different models help to clarify which structures are most likely to help define and apply concepts of EI.

\section{Limitations}

The present study tested the structure of a self-rating EI measure. As we have indicated in the introduction, self- 
Table 6

Regression Weights Regarding the Relationships Between the Three Factors and Sex, Age, and Education Level, As a Result of the Multiple-Indicators-Multiple-Causes (MIMIC) Analysis on the Three-Factor AES Questionnaire

\begin{tabular}{|c|c|c|c|}
\hline Factor $\leftarrow$ Exogenic Variable & $\begin{array}{c}\text { Unstandardized } \\
\text { Estimate }\end{array}$ & $\begin{array}{c}\text { Standard } \\
\text { Error }\end{array}$ & $p$ \\
\hline Appraisal of emotions $\leftarrow$ Gender & .269 & .061 & .000 \\
\hline Appraisal of emotions $\leftarrow$ Age & .002 & .002 & .244 \\
\hline Appraisal of emotions $\leftarrow$ Education level & -.011 & .016 & .485 \\
\hline Optimism and regulation of emotions $\leftarrow$ Gender & .082 & .065 & .210 \\
\hline Optimism and regulation of emotions $\leftarrow$ Age & -.002 & .002 & .362 \\
\hline Optimism and regulation of emotions $\leftarrow$ Education level & -.024 & .022 & .264 \\
\hline Intrapersonal and interpersonal utilization of emotions $\leftarrow$ Gender & .007 & .070 & .925 \\
\hline Intrapersonal and interpersonal utilization of emotions $\leftarrow$ Age & .000 & .002 & .925 \\
\hline Intrapersonal and interpersonal utilization of emotions $\leftarrow$ Education level & .000 & .004 & .926 \\
\hline
\end{tabular}

Note-Arrows show the direction of the relationship between the exogenic and the endogenic variables (factors) in the model.

rating questionnaires, in contrast to ability-based measures, represent only one type of the assessment of EI. Self-rating EI tests measure only the perceptions of persons regarding their own EI; therefore, self-knowledge, linguistic skills, self-esteem, and the need of social approval of the individual have a greater influence on the scores than do performance tests. Consequently, although self-rating questionnaires provide important information for a better understanding of the nature of EI, we have to emphasize that results of the present study refer exclusively to the concept of EI operationalized by self-rating measures.

\section{AUTHOR NOTE}

Z.D. acknowledges the support of the János Bolyai Research Scholarship of the Hungarian Academy of Sciences. Address correspondence to Z. Demetrovics, Eötvös Loránd University Institutional Group on Addiction Research, Izabella u. 46, Budapest, 1064 Hungary (demetrovics@, t-online.hu).

\section{REFERENCES}

AKaIKe, H. (1973). Information theory and an extension of the maximum likelihood principle. In B. N. Petrov \& F. Csáki (Eds.), Second International Symposium on Information Theory (pp. 267-281). Budapest: Akadémiai Kiadó.

Austin, E. J., Saklofske, D. H., \& Egan, V. (2005). Personality, wellbeing, and health correlates of trait emotional intelligence. Personality \& Individual Differences, 38, 547-558.

Austin, E. J., Saklofske, D. H., Huang, S. H. S., \& McKenney, D. (2004). Measurement of trait emotional intelligence: Testing and cross-validating a modified version of Schutte et al.'s (1998) measure. Personality \& Individual Differences, 36, 555-562. doi:10.1016/ S0191-8869(03)00114-4

BARCHARD, K. A. (2003). Does emotional intelligence assist in the prediction of academic success? Educational \& Psychological Measurement, 63, 840-858. doi:10.1177/0013164403251333

BAR-ON, R. (1997). The Bar-On Emotional Quotient Inventory (EQ-i): A test of emotional intelligence. Toronto: Multi-Health Systems.

Briggs, S. R., \& CHEEK, J. M. (1986). The role of factor analysis in the development and evaluation of personality scales. Journal of Personality, 54, 106-148. doi:10.1111/j.1467-6494.1986.tb00391.x

BROWN, T. A. (2006). Confirmatory factor analysis for applied research. New York: Guilford.

Browne, M. W., \& CUDECK, R. (1993). Alternative ways of assessing model fit. In K. A. Bollen \& J. S. Long (Eds.), Testing structural equation models (pp. 136-162). Newbury Park, CA: Sage.

Caruso, D. R., Mayer, J. D., \& Salovey, P. (2002). Relation of an ability measure of emotional intelligence to personality. Journal of Personality Assessment, 79, 306-320.
Chamorro-Premuzic, T., Bennett, E., \& Furnham, A. (2007). The happy personality: Mediational role of trait emotional intelligence. Personality \& Individual Differences, 42, 1633-1639. doi:10.1016/ j.paid.2006.10.029

Chen, F., Curran, P. J., Bollen, K. A., Kirby, J., \& Paxton, P. (2008). An empirical evaluation of the use of fixed cutoff points in RMSEA test statistic in structural equation models. Sociological Methods \& Research, 36, 462-494.

Gignac, G. E., Palmer, B. R., Manocha, R., \& Stough, C. (2005). An examination of the factor structure of the Schutte Self-report Emotional Intelligence (SSREI) scale via confirmatory factor analysis Personality \& Individual Differences, 39, 1029-1042. doi:10.1016/ j.paid.2005.03.014

Goleman, D. (1995). Emotional intelligence. New York: Bantam.

Keele, S. M., \& Bell, R. C. (2008). The factorial validity of emotional intelligence: An unresolved issue. Personality \& Individual Differences, 44, 487-500.

KLINE, R. B. (2005). Principles and practice of structural equation modeling. New York: Guilford.

Lane, R. D., Quinlan, D. M., Schwartz, G. E., Walker, P. A., \& Zeitlin, S. B. (1990). The Levels of Emotional Awareness Scale: A cognitive-developmental measure of emotion. Journal of Personality Assessment, 55, 124-134.

MARSH, H. W., \& HocEVAR, D. (1985). The application of confirmatory factor analysis to the study of self-concept: First- and higher-order factor structures and their invariance across groups. Psychological Bulletin, 97, 562-582. doi:10.1037/0033-2909.97.3.562

Martinez-Pons, M. (1997). The relation of emotional intelligence with selected areas of personal functioning. Imagination, Cognition \& Personality, 17, 3-13. doi:10.2190/68VD-DFXB-K5AW-PQAY

MaYer, J. D., Caruso, D., \& Salovey, P. (1999). Emotional intelligence meets traditional standards for an intelligence. Intelligence, 27, 267-298. doi:10.1016/S0160-2896(99)00016-1

Mayer, J. D., Salovey, P., \& Caruso, D. R. (2002). Mayer-SaloveyCaruso Emotional Intelligence Test (MSCEIT), Version 2.0. Toronto: Multi-Health Systems.

Nagy, H., Oláh, A., \& Tóth, K. G. (2009). Az érzelmi intelligencia mérésének néhány problémája: A fejlődési kritérium tesztelése [Some problems of the measurement of the emotional intelligence: The testing of the developmental criterion]. Pszichológia, 29, 165186. doi:10.1556/Pszicho.29.2009.2.5

Palmer, B. R., Gignac, G., Manocha, R., \& Stough, C. (2005). A psychometric evaluation of the Mayer-Salovey-Caruso Emotional Intelligence Test Version 2.0. Intelligence, 33, 285-305. doi:10.1016/ j.intell.2004.11.003

Parker, J. D. A., Summerfeldt, L. J., Hogan, M. J., \& Majeski, S. A. (2004). Emotional intelligence and academic success: Examining the transition from high school to university. Personality \& Individual Differences, 36, 163-172.

Petrides, K. V., \& Furnham, A. (2000). On the dimensional structure of emotional intelligence. Personality \& Individual Differences, 29, $313-320$. 
Saklofske, D. H., Austin, E. J., \& Minski, P. S. (2003). Factor structure and validity of a trait emotional intelligence measure. Personality \& Individual Differences, 34, 707-721. doi:10.1016/S0191 -8869(02)00056-9

Salovey, P., Bedell, B. T., Detweiler, J. B., \& Mayer, J. D. (1999). Coping intelligently: Emotional intelligence and the coping process. In C. R. Snyder (Ed.), Coping: The psychology of what works (pp. 141-164). New York: Oxford University Press.

Salovey, P., \& Mayer, J. D. (1990). Emotional intelligence. Imagination, Cognition \& Personality, 9, 185-211.

Salovey, P., Stroud, L. R., Woolery, A., \& Epel, E. S. (2002). Perceived emotional intelligence, stress reactivity, and symptom reports: Further explorations using the trait meta-mood scale. Psychology \& Health, 17, 611-627.

Schutte, N. S., Malouff, J. M., \& Bhullar, N. (2009). The Assessing Emotions Scale. In C. Stough, D. H. Saklofske, \& J. D. A. Parker (Eds.), Assessing emotional intelligence: Theory, research, and application (pp. 119-134). New York: Springer.
Schutte, N. S., Malouff, J. M., Hall, L. E., Haggerty, D. J., CooPER, J. T., Golden, C. J., \& Dornheim, L. (1998). Development and validation of a measure of emotional intelligence. Personality \& Individual Differences, 25, 167-177.

TsAousis, I., \& NiKOLAOU, I. (2005). Exploring the relationship of emotional intelligence with physical and psychological health functioning. Stress \& Health, 21, 77-86.

VAN Der Zee, K., ThiJs, M., \& Schakel, S. F. (2002). The relationship of emotional intelligence with academic intelligence and the Big Five. European Journal of Personality, 16, 103-125.

\section{SUPPLEMENTAL MATERIALS}

Large, single-page versions of Tables 4 and 5 may be downloaded from http://brm.psychonomic-journals.org/content/supplemental.

(Manuscript received April 29, 2009;

revision accepted for publication January 18, 2010.) 